\title{
Calculated and experimental estimation of preliminary loading effect at elevated temperatures on fracture toughness of pressure vessel materials
}

\author{
Smimov, V.I., Timofeev, B.T. \\ Central Research Institute of Structural Materials "Prometey", St. Petersburg, Russia
}

\begin{abstract}
Basing on the analysis of different factors effect on the structural materials cracking resistance after prelimenary heat loading or warm prestressing (WPS), a conclusion has been drawn that the existing calculation models used for for WPS effect prediction are limited, and the Chell model, which is very convenient for practical use, in particular.

The testing results on cracking resistance of the structural 15X2MFA (of different strengths steel) and 15X2HMFA steels as well as a welding 10XMFT joint after WPS are presented.

Comparison of the experimental and calculation data proved the possibility of practical application of the simplified Chell solution of the WPS effect on the structural steels cracking resistance in the wide range of loading up to the subcritical crack growth.
\end{abstract}

\section{INTRODUCTION}

A structure warm prestressing (WPS) is performed as a rule at temperature, exceeding operating temperature, and is aimed to increase fracture toughness of a structure, containing initial defects (the sizes of which are smaller than those, registered by NDT techniques) as well as defects, which were not casually revealed by NDT procedures. The positive WPS effect on structural material corrosion strength is confirmed by numerous experimental investigations. This positive effect after WPS is evident even in those cases, when loading at elevated temperature is lower than fracture loading by test temperature without WPS (Long 1986).

By the investigation of WPS effect on structural material fracture toughness, there main cycles of the variation of loading and temperature are usually used:

LCF - preliminary loading at $T_{1}$ temperature; cooling to $T_{3}$ temperature; testing to failure;

LCUF - preliminary loading at $T_{1}$ temperature; cooling to $T_{3}$ temperature; unloading; testing to failure;

LUCF - preliminary loading at $T_{1}$ temperature; unloading at $T_{1}$; cooling to $T_{3}$ temperature; testing to failure.

Usually WPS temperature is selected with the aim to provide material ductile behaviour by loading; WPS level and cycle type are determined either by stresses and temperatures by structure testing or by the regimes of temperature and loading variation in a structure (for example, in pressure vessels during cooling by emergency repair).

There are several well-known models (Chell 1977, 1981; Carry 1981; Smith 1990), describing WPS influence on brittle fracture resistance. However, all of them are in some degree limitted; because they base as a rule only on one or two well-known mechanisms, increasing fracture toughness after WPS (Nickols 1968). In development of residual compressive stresses at the crack tip after WPS is not enough to be taken as the main factor (as it is done in (Brazerc 1963, Harrison 1972), as it is known (Andrews 1970), that the maximum WPS effect appears in LCF cycle, when unloading and consequently residual stress field are absent. The contribution of crack blunting in crack resistance after WPS is also estimated discrepantly (Mudry 1985). The influence of strain hardening on WPS effect was investigated in (Long 1986), where due to the calculations it was 
shown,that disregard of total strain hardening in Chell's and Carry's models did not sufficiently influence on results. Chell'smodel is recommended for practical application.

The contradiction of given results, concerning the effect of various factors on WPS attack is explained by the fact that the contribution of these factors to fracture toughness increase after WPS depends on preliminary loading level (Beremin 1981). By LUCF cycle and relatively low loading levels, the role of residual stresses becomes important. However, with preliminary loading increase, the effect of crack blunting and strain hardening also increases (Mudry 1985).

In this condition a possibility to estimate WPS effect on Chell's model as a very convinient (Chell 1980) from the practical point of view becomes by interesting high level of preliminary loading, when crack blunting and strain hardening are of great importance - the factors, which are not taken into account in Chell's model.

This paper considers the problems of Chell's model practical application to estimate WPS effect for VVER pressure vessel material.

\section{CHELL'S MODEL OF WPS}

Chell's model is based on the suggestion, that the main WPS effect is yield strength variation, and consequently residual zones generation. By this, the model may be used in any case of yield strength variation, while the structure is under loading - which is the result of temperature variation, irradiation affect or other factors (Carry 1981). Basing on the analysis of the development and variation of residual compressive stress and strain zones at the crack tip for various stages of loading by WPS, Chell and his colleagues (Chell 1981) showed, that WPS effect was connected with the realization of «active* plastic zone, which includes only «mobile dislocations.

In this case WPS effect is estimated differently, depending on the characteristical size of varying plastic zone: $S_{1}$ - by initial loading at temperature $T_{1}$ and yield strength $\sigma_{1} ; S_{2}$ - by unloading and cooling (temperature $T_{2}$, yield strength $\sigma_{2}$ ); $S_{3}$ - by testing to failure (temperature $T_{3}$ and yield strength $\sigma_{3}$ ).

By this, three cases are possible:

or

$$
\mathrm{S}_{1}>\mathrm{S}_{2}>\mathrm{S}_{3}
$$

$$
\begin{gathered}
\sigma_{1} / \bar{\sigma}_{1}>\left(\sigma_{1}-\sigma_{2}\right) /\left(\bar{\sigma}_{1}+\bar{\sigma}_{2}\right)>\left(\sigma_{3}-\sigma_{2}\right) /\left(\bar{\sigma}_{3}+\bar{\sigma}_{2}\right) \\
\mathrm{S}_{1}>\mathrm{S}_{3}>\mathrm{S}_{2}
\end{gathered}
$$

or

$$
\begin{aligned}
& \sigma_{1} / \bar{\sigma}_{1}>\left(\sigma_{3}-\sigma_{1}\right) /\left(\bar{\sigma}_{3}-\vec{\sigma}_{1}\right)>\left(\sigma_{3}-\sigma_{2}\right) /\left(\bar{\sigma}_{2}+\bar{\sigma}_{3}\right)>\left(\sigma_{1}-\sigma_{2}\right) /\left(\bar{\sigma}_{1}+\bar{\sigma}_{2}\right) \\
& S_{3}>S_{2}>S_{2} \\
&\left(\sigma_{3}-\sigma_{1}\right) /\left(\bar{\sigma}_{3}-\bar{\sigma}_{1}\right)>\sigma_{1} / \bar{\sigma}_{1}>\left(\sigma_{3}-\sigma_{2}\right) /\left(\bar{\sigma}_{2}+\bar{\sigma}_{3}\right)>\left(\sigma_{1}-\sigma_{2}\right) /\left(\bar{\sigma}_{1}+\bar{\sigma}_{2}\right)
\end{aligned}
$$

For each case, the stress intensity factor $K_{1}=K_{3}$, characterizing fracture conditions at $T_{3}$ after WPS with unloading up to $\mathrm{K}_{2}$ may be found from the solution of the following equations:

$$
\begin{aligned}
& \text { Case } K_{I C}^{l}=\bar{\sigma}_{3}\left[\frac{K_{1}^{2}}{\sigma_{1}}\left(1-f_{32}\right)-\frac{\left(K_{1}-K_{2}\right)^{2}}{\sigma_{1}+\sigma_{2}}\left(1-f_{21}\right)+\frac{\left(K_{3}-K_{2}\right)^{2}}{\sigma_{2}+\bar{\sigma}_{3}}\right] \text {, } \\
& \text { where } \quad f_{32}=\varphi\left(z=\left[\frac{\left(K_{3}-K_{2}\right) \sigma_{l}}{\left(\sigma_{2}+\sigma_{3}\right) K_{l}}\right]^{2}\right) \text {, } \\
& f_{21}=\varphi\left(Z_{1}=\left[\frac{\left(K_{3}-K_{2}\right)\left(\bar{\sigma}_{1}+\bar{\sigma}_{2}\right)}{\left(\bar{\sigma}_{3}+\bar{\sigma}_{2}\right)\left(\bar{K}_{1}-K_{2}\right)}\right]^{2}\right) \text {. } \\
& \text { Case } K_{I C}^{2}=\bar{\sigma}_{s}\left[\frac{\left(K_{3}-K_{1}\right)^{2}}{\left(\bar{\sigma}_{3}-\bar{\sigma}_{1}\right) K_{1}}+\frac{K_{1}^{2}}{\sigma_{1}}\left(1-f_{31}\right)\right] \text {, } \\
& f_{31}=\varphi\left(z=\left[\frac{\left(K_{3}-K_{1}\right) \bar{\sigma}_{1}}{\left(\bar{\sigma}_{3}-\bar{\sigma}_{1}\right) K_{1}}\right]^{2}\right)
\end{aligned}
$$

$$
K_{3}=K_{I C}
$$


where

$$
\varphi(z)=(1-z)^{1 / 2}-\frac{z}{2} \ln \left[\frac{1+(1-z)^{1 / 2}}{1-(1-z)^{1 / 2}}\right] .
$$

where $K_{1}$ is the stress intensity factor (SIF) resulting from overload,

$\mathrm{K}_{2}$ is the value after unloading ,

$\mathrm{K}_{3}$ is the reloaded level, when fracture takes place. It is impossible to know beforehand, which of these three cases will be realized. Therefore it is necessary to solve the equations (4), (5), (6) and then basing on the conditions (1) - (3) to define the case, being realyzed, for which the value $\mathrm{K}_{3}$ is calculated fracture stress intensity factor after WPS. It should be noted, that the value $\mathrm{K}_{3}$ is not expressed from calculated dependences quite evidently and it is necessary to use numerical methods of equation solution to find it.

The equation may be approximated with a sufficient correctness by the relation (Chell 1980 , Kotilainen 1983):

$$
\varphi(z)=(1-z)^{2}
$$

Then the equations (4)-(6) may be rewritten as related to $K_{3}$.

$$
\begin{aligned}
& \text { Case } 1 \\
& K_{3}=K_{2}+\left(\bar{\sigma}_{3}+\bar{\sigma}_{2}\right) K_{1}\left\{\frac{\left(\bar{\sigma}_{3}-\bar{\sigma}_{2}\right)\left(K_{1}-K_{2}\right)^{2}}{2\left[K_{1}^{2}\left(\bar{\sigma}_{1}+\bar{\sigma}_{2}\right)^{3}-\left(K_{1}-K_{2}\right) \bar{\sigma}_{3}^{3}\right.}\left[\frac{4 K_{10}^{2}\left[K_{1}^{2}\left(\bar{\sigma}_{1}+\bar{\sigma}_{2}\right)^{3}-\left(K_{1}-K_{2}\right)^{2} \bar{\sigma}_{1}^{3}\right.}{\bar{\sigma}_{3}^{3}\left(\bar{\sigma}_{3}-\bar{\sigma}_{2}\right)^{2} K_{1}^{2}\left(K_{1}-K_{2}\right)}+1\right]\right\}(9) \\
& \text { Case } 2 \\
& \text { Case } 3
\end{aligned}
$$

After $K$ calculation on «simplified dependences $(9)-(11)$ it is also necessary to verify on the conditions (1)-(3) and to define the fracture stress intensity factor.

The performed analysis (Chell 1986a) of calculated dependences permitted Chell to suggest the approximated formula for the estimation of fracture stress intensity factor after warm prestressing

where

$$
\Delta \mathrm{K}_{\mathrm{R}}=0.20 \Delta \mathrm{K}_{\mathrm{U}}+0.87 \mathrm{~K}_{\mathrm{IC}}
$$

The condition of correctness on the formula (12) is:

$$
\Delta K_{\mathrm{u}}=\mathrm{K}_{1}-\mathrm{K}_{2}, \Delta \mathrm{K}_{\mathrm{R}}=\mathrm{K}_{3}-\mathrm{K}_{2} \text {. }
$$

$$
\Delta K_{R} / \Delta K_{U} \leq 1 .
$$

A program was developed for computer calculations.

The initial data for calculations are loading temperatures $T_{1}, T_{2}, T_{3}$, material yield strength at these temperatures $\bar{\sigma}_{1}, \bar{\sigma}_{2}, \bar{\sigma}_{3}$ and stress intensity factors for the first two loading stages and material fracture toughness $\mathrm{K}_{\mathrm{IC}}$ at $\mathrm{T}_{3}$ temperature.

\section{CALCULATION AND EXPERIMENTAL RESULTS AND THEIR DISCUSSION}

Investigation results concerning WPS effect on fracture toughness of the types $15 \mathrm{X} 2 \mathrm{HMFA}$ and 15X2MFA structural steels (of various strength level) and $15 \times 2 M F A$ welded joint are given together with calculation results with the use of the equations, described above. One of the investigation tasks is also to estimate the influence of before critical crack growth on WPS effect at the stage of preliminary loading. Mechanical properties and fracture toughness characteristics of investigated materials are given in Table, where $\mathrm{K}_{i}$ the maximum value of stress intensity factor at the moment of crack starting at $T_{1}$ temperature (based on the test results of four specimens), fracture toughness characteristics were determined by compact specimens of $50 \mathrm{~mm}$ thickness, containing cracks. To realize conditions of plain strain at $T_{3}$ temperature, sharp notches were made on 15X2HMFA steel specimens.

The definition of $K_{i}$ parameter was performed by acoustic emission registration with AF-11 device in accordance with the procedure, published in (Smirnov 1979). Preliminary loading was carried out on three main schemes LUCF. 
Mechanical properties of investigated materials.

Table.

\begin{tabular}{|c|c|c|c|c|c|c|c|c|c|}
\hline \multirow[b]{2}{*}{ Materials } & \multirow[b]{2}{*}{$\begin{array}{l}\text { Strenglh } \\
\text { level }\end{array}$} & \multicolumn{4}{|c|}{ At $+20^{\circ} \mathrm{C}$} & \multirow[b]{2}{*}{$\begin{array}{l}T_{1} \\
{ }^{\circ} \mathrm{C}\end{array}$} & \multirow[b]{2}{*}{$\begin{array}{c}K_{1}^{\min } \\
\text { MPavm }\end{array}$} & \multirow[b]{2}{*}{$\begin{array}{l}\mathrm{T}_{3} \\
{ }^{\circ} \mathrm{C}\end{array}$} & \multirow[b]{2}{*}{$\begin{array}{c}\mathrm{K}_{\mathrm{ic}} \\
\text { MPavin }\end{array}$} \\
\hline & & $\begin{array}{l}\text { UTS } \\
\mathrm{MPa}\end{array}$ & $\begin{array}{c}\mathrm{YS} \\
\mathrm{MPa}\end{array}$ & $\begin{array}{l}\text { A } \\
\%\end{array}$ & $\begin{array}{l}\mathrm{Z} \\
\%\end{array}$ & & & & \\
\hline \multirow[t]{2}{*}{$\begin{array}{c}\text { Base metal } \\
15 \times 2 M F A\end{array}$} & KP40 & 994 & 440 & 16 & 65 & $\begin{array}{r}+25 \\
+25 \\
+25 \\
+100 \\
+150 \\
+300 \\
\end{array}$ & $\begin{array}{c}- \\
- \\
- \\
139 \\
139 \\
139\end{array}$ & $\begin{array}{r}-170 \\
-150 \\
-50 \\
+20 \\
+20 \\
+20 \\
\end{array}$ & $\begin{array}{l}39 \\
42 \\
56 \\
81 \\
81 \\
81\end{array}$ \\
\hline & KPIO0 & 1199 & 1063 & 16 & 64 & $\begin{array}{r}+100 \\
+150 \\
+300 \\
\end{array}$ & $\begin{array}{l}127 \\
127 \\
127 \\
\end{array}$ & $\begin{array}{l}+20 \\
+20 \\
+20 \\
\end{array}$ & $\begin{array}{l}99 \\
99 \\
99\end{array}$ \\
\hline $\begin{array}{r}\text { Base metal } \\
15 \times 2 \mathrm{HMFA} \\
\end{array}$ & KP80 & 941 & 816 & 16 & 68 & $\begin{array}{r}+150 \\
+300 \\
\end{array}$ & $\begin{array}{l}140 \\
140 \\
\end{array}$ & $\begin{array}{r}+20 \\
+20 \\
\end{array}$ & $\begin{array}{l}106 \\
106 \\
\end{array}$ \\
\hline $\begin{array}{c}\text { Weld metal } \\
\text { (wire Cb-10XMFT) }\end{array}$ & KP60 & 831 & 692 & 15 & 62 & +150 & 90 & +20 & 74 \\
\hline
\end{tabular}

Test results are given in Fig. 1 as relations of $K_{t} / K_{t C}$ versus $K_{1} / K_{i}$ characterizing the level of preliminary loading, and by $K_{1} / K_{i}>1$ also the level of before-critical crack growth, because $K_{1}$ was defined with the consideration of revealed crack growth on specimen fracture. Fig. 1 indicates, that in the given coordinates practically all test results are in one scatter band. The exception is 15X2MFA (KP80) steel test results. For this steel at $T_{3}=20^{\circ} \mathrm{C}$ the conditions of correctness of $K_{\mathrm{IC}}$ definition were not realized, and as a calculation value the relative value $\mathrm{K}_{\mathrm{Q}}$ was taken. Besides, it is well known (Smith 1990), that by fracture under the conditions of plane strained state the positive WPS effect is sufficiently higher, than in conditions of plain strain. The same investigations were also performed in (Troshchenko 1992, Pokrovsky 1993).

It should be noted, that in contrast to the available concepts (Mudry 1985,Carry 1983). before critical crack growth does not reduce positive WPS effect at the stage of preliminary loading. It permits to select correctly $T_{1}$ temperature, preliminary loading, which should be higher that the critical $T_{\mathrm{K} 2}$ temperature, by lower temperature fracture takes place without before-critical crack growth (Karzov 1989). $\mathrm{T}_{\mathrm{K} 2}$ temperature separates the range of brittle fracture from the range of quasi-brittle and tough fracture and can be determined by tests on impact bend of standard Charpy specimens with the division of fracture work on constituents (Smirnov 1992). Besides, test results indicate, that unloading degree practically does not influence on WPS effect for 15X2HMFA and 15X2MFA (KP100) steels. It permits to draw a conclusion about an insignificant residual stress influence on WPS effect in the plastic flow zone near the crack tip for these steels.

Calculated values of stress intensity factors at fracture after preliminary loading on Chell's model solution with equations (4) - (6), simplified formula (9) - (11) and approximate estimation equations (12), (13) are given in Fig.2. The comparison shows, that the best agreement with experimental results is given by calculations on "simplified» formula (Fig.2,b). It is especially evident by LUCF loading cycles. And only by the presence of significant before-critical growth the simplified solutions give lower results.

The consideration of correction on plastic zone permits to to increase somewhat the exactness of estimation by the calculation of $\mathrm{K}_{\mathrm{p}}$ (Fig.2,b). At the same time the correct estimation gives more conservative results even for LUCF (Fig.2,a). The greatest declining to the conservative side are obtained by the calculation on the estimation formula (Fig.2,b). It should be noted that here the correction condition for loading cycles LCF $(12)$ is not realized.

It is recommended to calculate WPS effect on fracture stress intensity factors to perform on the dependences (9) - (11), as they are more convinient for calculations and give results close to experiment values of calculated loading by all types of loading, even by before critical crack incipient growth during preliminary loading. 


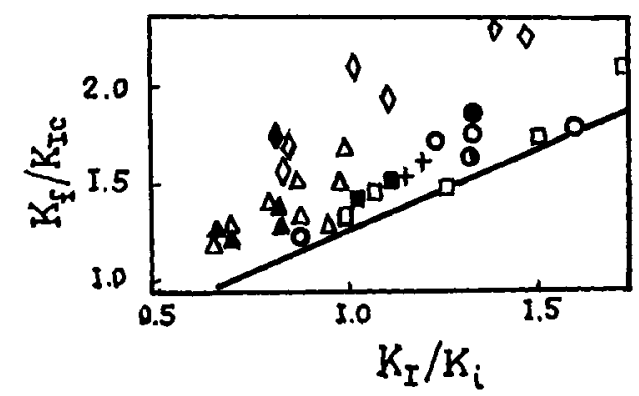

Fig.1. Fracture toughness $\mathrm{K}_{\mathrm{t}} / \mathrm{K}_{\mathrm{tC}}$ dependence on preliminary thermal loading $\mathrm{K}_{\mathrm{t}} / \mathrm{K}_{\mathrm{i}}$ :

$\checkmark,-15 X 2 \mathrm{MFA}$ steel (YS $=889 \mathrm{MPa})$, LUCF cycles with total and partial unloading;

$\square,+, 1$ - 15X2MFA steel (YS $=1063 \mathrm{MPa})$, LUCF cycles with total and partial unloading and LCF cycles, respectively;

$\triangle, \triangle-15 X 2 H M F A$ steel LUCF and LCF cycles, respectively;

$0,0,0$ - weld metal (wire Cb-10XMFT), LUCF cycles (with total and partial unloading) and LCF, respectively.
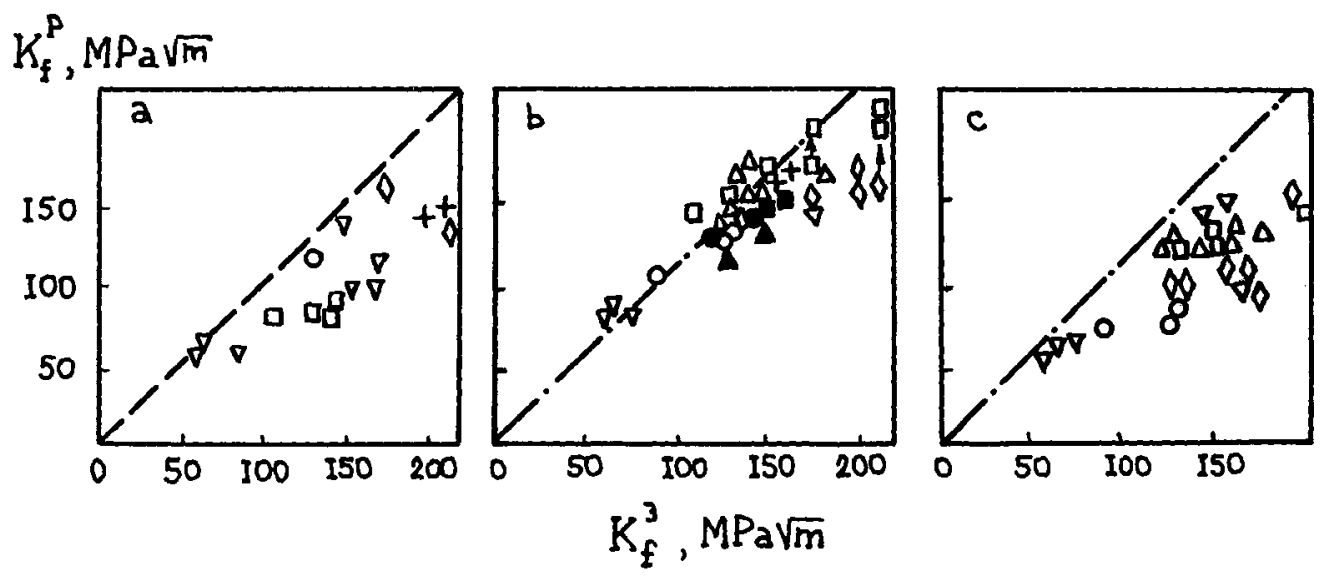

Fig.2. Comparison of experimental data $\mathrm{K}_{\mathrm{f}}^{3}$ at fracture after WPS and calculation results on Chell's model $\mathrm{K}_{\mathrm{i}}^{\mathrm{p}}$ :

a) on exact formulas (4) - (6);

b) on simplified formulas (9) - (11);

c) on approximate formulas (12), (13)

$\nabla, 0,0 \cdot 15 \times 2 M F A$ steel $(Y S=440 ; 880 ; 1063 \mathrm{MPa}$ ), respectively;

$\triangle, O-15 X 2 H M F A$ steel and weld metal (wire Cb-IOXMFT), respectively.

Other index same like on Fig.1.

The estimation formula may be used by LUCF cycles taking into account the conservatism of its results and that it is not necessary to have initial information about the values of yield stress for materials and the absolute level of stress intensity (in formulas only diferences $K_{1}, K_{2}, K_{3}$ ). It permits to estimate WPS effect from useful loading by the presence of residual stresses in structure.

By WPS effect estimation it is necessary to take into consideration the factors which can sharply reduce WPS positive effect, strain hardening and cyclic loading between WPS stage and testing (Chell 1986b). 


\section{CONCLUSION}

The obtained results shows the possibility of Chell's model practical application to predict WPS effect on pressure vessel steel fracture toughness in the wide range of its level up to the significant before-critical crack growth. The better agreement with experimental data is altained with the use of Chell's simplified formulas.

\section{REFERENCES}

Andews, W.R. 1970. Effect of loading sequence on notches strength of warm prestressing alloy steel. Trans. ASME, J.Eng.Ind., Nov. :785-791.

Bermin, E.M. 1981. Numerical modelling of warm prestress effec using a damage function for cleavage fracture. Advances in Fracture Research. Proc. 5th Conf Fracture. vol.2, :825.832.

Brazerc V., Ukava T. 1963. The influence of prestressing on notched strength specimen. Trans. ASME, J.Bas. Eng., vol.85, nr.1, :116-118.

Carry, D.A. 1981. A micromechanic approach the warm prestressing of ferritic steels. Int.J.Fracture, vol.17, nr. $3,: 335-343$

Carry, D.A. 1983. A model for predicting the influence of warm pre-stressing and strain ageing on the clevage fracture toughness of ferritic steels. Int.J. Fracture, vol.22, nr.2, :145-159.

Chell, G.G., Vitek V. 1977. The J-integral as a fracture criterion: perhaps in doesn't mean what you thought it mean. Int.J.Fracture, vol.13, nr.7, :882-886.

Chell, G.G. 1980. Some fracture mechanics applications of warm prestressing to pressure vessels. Proc. 4th Conf. Pressure Technology, London, :117-124.

Chell, G.G., Haigh I.R., Vitek V.A. 1981. A theory of warm prestressing: experimental validation and the implication for elastic-plastic failure criteria. Int.J.Fracture, vol.17, nr.1,:61-82.

Chell, G.G., Haigh I.R. 1986a. The effect of warm prestressing on proof tested pressure vessels. Int.J.Pressure Vessels and Piping, vol.23, nr.2, :121-131.

Chell, G.G. 1986b. The effect of sub-critical growth on the fracture behaviour of cracked ferritic steels after warm prestressing. Fatigue Fracture Eng. Material and Structure, vol.9, nr.4, :259-274.

Harrison, T.C., Fearnchough G.D. 1972. The influence of warm prestressing on the brittle fracture of structure containing sharp defects. Trasactions ASME, J.Bas.Eng., vol.94, :373-405.

Karzov, G.P., Smirnov V.I., Timofeev B.T. 1989. On determination of critical brittle temperature under crack resistance testing. Physical-chemical mechanics of materials, nr.5, :54-59.

Kotilainen $\mathrm{H}$. 1983. The estimation of the benefical effect of a warm prestress during the emergency cooling of nuclear pressure vessel. KTM/GKAE Seminar, Moscow, 7.11 February 1983.

Long B. 1986. Strain hardening effects on the warm prestress of ferritic steels. Fracture control of engineering structure. ECF.6, vol.1, :351-362.

Mudry F. 1985. Cleavage fracture and transition: application the warm prestress effect. Elastic Plastic Fracture Mechanics: Proc. 4th Adv. Seminar, :303-325

Nickols, R.W. 1968. The use of overstress techniques. British Welding Journal, nr.1:21-42; nr. $2: 75-85$.

Pokrovsky V.V. et al. 1993. A promising method for enhancing resistance of pressure vessels to brittle fracture. Trans. of the scientific and practical seminar, 15-18 March 1993, St.Petersburg, :215-252.

Smirnov, V.I. 1979. Evaluation size of defects by acoustic emission techniques used by liniar elastic fracture mechanics. Defectoscopia, nr.2, :45-50.

Smirnov V.I., Deich A.S. 1992. On the determination of critical temperature of brittleness during impact bending. Physico-chemical mechanics of materials, vol.27, nr.2, :70-74.

Smith D.I., Garwood S.I. 1990. The significance of prior overload on fracture resistance a critical review. Int.J.Pressure Vessel and Piping. vol.41, nr.3, :255-296.

Troshchenko, V.T. et al. 1992. The effect of metallurgical factors on crack resistance of pressure vessel materials. Nuclear Eng. and Design, nr.3, :306-321. 